\title{
Una mujer trasplantada de pulmón con lesiones en el cuerpo y las uñas
}

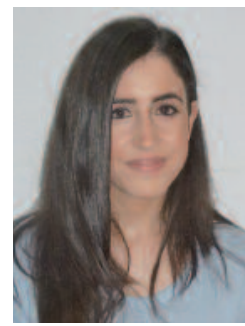

\section{Virginia Velasco Tamariz}

Médico interno residente de Dermatología.

Hospital Universitario 12 de Octubre. Madrid.

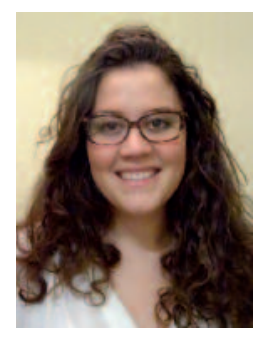

\section{Marta Prieto Barrios}

Médico interno residente de Dermatología.

Hospital Universitario 12 de Octubre. Madrid.

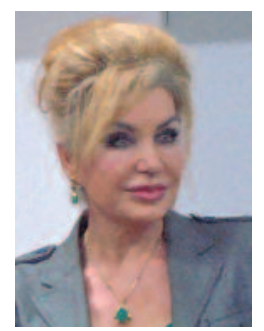

\section{Aurora Guerra Tapia}

Jefa de Sección de Dermatología. Hospital Universitario 12 de Octubre. Madrid.

Profesora titular de Dermatología Médico-quirúrgica y Venereología. Universidad Complutense. Madrid.
Mi paciente es una mujer de 64 años que hace un año volvió a nacer. Tras una larga enfermedad incapacitante y varios años en lista de espera, fue trasplantada del pulmón derecho. Por este motivo, su lista de medicación se había ampliado en los últimos meses, incluyendo varios tratamientos inmunosupresores.

Sin embargo, ahora venía a la consulta por un motivo que ella consideraba banal: notaba que sus uñas habían cambiado de aspecto en los últimos meses.

Al mostrarnos las manos, se objetivaba una decoloración blanco-amarillenta del lecho distal de varias de las uñas de la mano derecha, con hiperqueratosis subungueal (fig. 1).

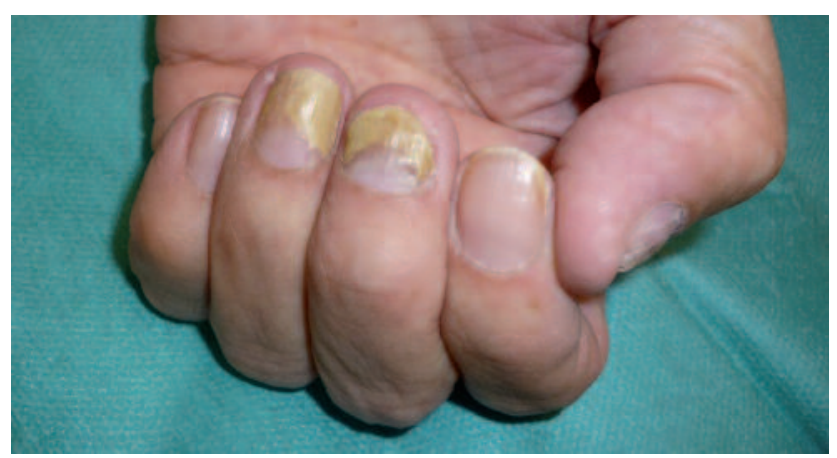

Figura 1. Onicomicosis. Forma subungueal distal-lateral.

Algunas uñas de los pies se encontraban también afectadas, observándose engrosamiento de la placa ungueal, onicólisis distal e, incluso, distrofia ungueal en algunas de ellas.

Sin embargo, nuestra sorpresa fue mayúscula al explorar por completo a la paciente y encontrar extensas placas eritematodescamativas en la parte anterior del tórax y las ingles (fig. 2), que se extendían confluyendo en el abdomen y descendían hacia los muslos (fig. 3). 


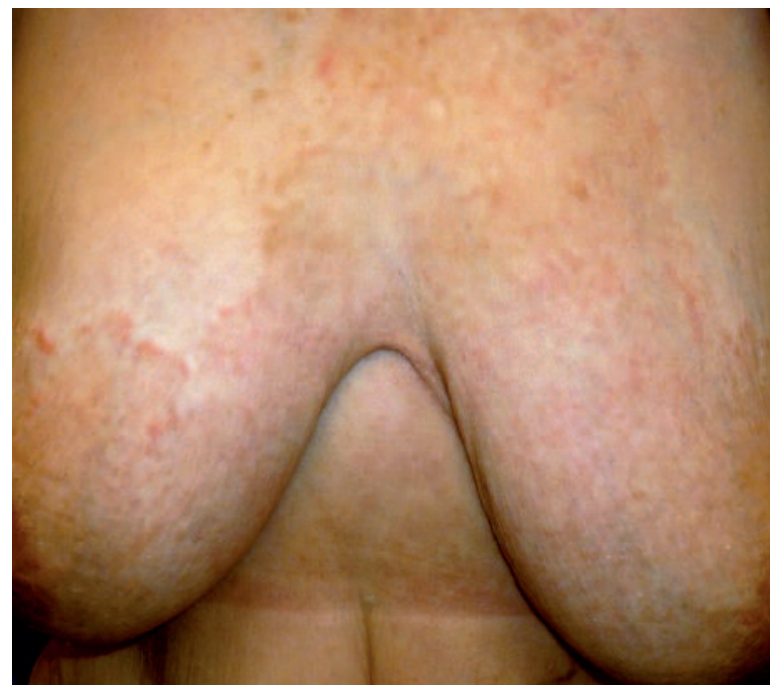

Figura 2. Tiña corporal.

$\mathrm{Al}$ observarlas con más detalle, era evidente un borde activo, más papuloso y eritematoso que el resto de la lesión.

$\mathrm{Al}$ preguntar a la paciente por estas lesiones, reconoció que le habían pasado inadvertidas, aunque sí reconocía un prurito prácticamente constante desde hacía varios meses, al que no había dado importancia.

Ante las características morfológicas de las lesiones, y dada la alta sospecha clínica de infección fúngica, tomamos muestras microbiológicas para observación directa y cultivo.

Realizamos un examen directo al microscopio mediante preparación con hidróxido potásico al $10 \%$, visualizándose numerosas hifas septadas. A las tres semanas, se cultivó Trichophyton rubrum en todas las localizaciones.

Las dermatofitosis o tiñas son infecciones producidas por hongos filamentosos queratinofílicos. Afectan al estrato córneo de la epidermis, al pelo y a las uñas.

Según cuál sea su reservorio, podemos clasificarlos en tres grupos: geofílicos, antropofílicos y zoofílicos ${ }^{1}$.

Asimismo, se distinguen tres géneros: Tricho phyton, Microsporum y Epidermophyton.

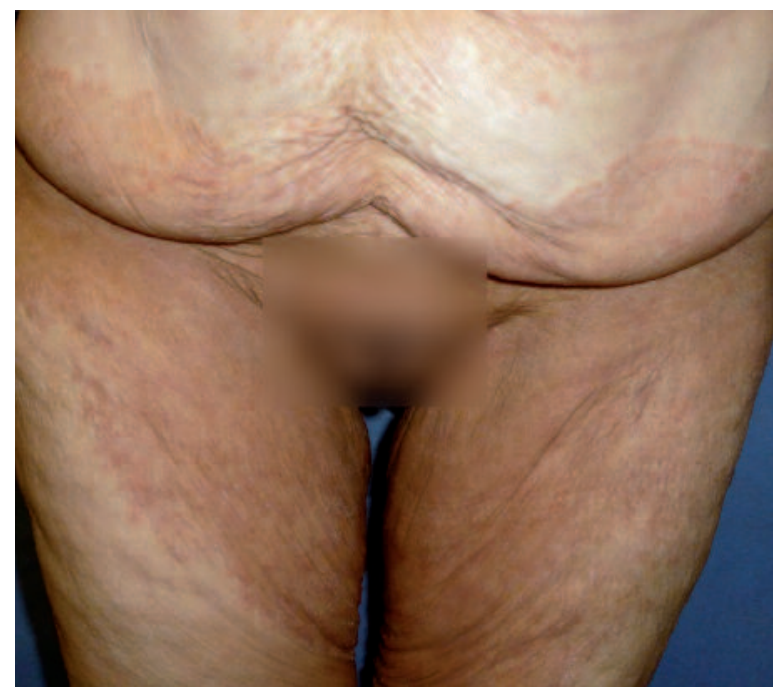

Figura 3. Tiña inguinal. Extensión al tronco y a las extremidades.

Trichophyton rubrum es el dermatofito antropofílico más frecuentemente aislado en la práctica clínica. Se considera el principal agente etiológico de la tiña del pie, la onicomicosis, la tiña inguinal y la tiña corporal ${ }^{2}$.

La tiña del cuerpo, en el pasado conocida como «herpes circinado», incluye todas las infecciones por dermatofitos que afectan a la piel lampiña del tronco y las extremidades, a excepción de las localizadas en áreas específicas, como las palmas, las plantas o las ingles, que, por sus peculiaridades, reciben denominaciones específicas ${ }^{3}$.

Aunque puede manifestarse de múltiples formas, la más frecuente comienza como una pequeña lesión eritematodescamativa, que se extiende centrífugamente y da lugar a placas circulares $\mathrm{u}$ ovaladas, pruriginosas, eritematosas y con descamación superficial, adquiriendo formas anulares o policíclicas, con un centro más pálido (representando la resolución de la infección) y un borde marcado, elevado y eritematoso, que puede presentar pápulas, escamas, vesículas y costras ${ }^{3}$.

Son factores de riesgo el contacto con animales infectados, lo que es habitual en niños, los ambientes cálidos y húmedos, y el contagio por fómites (objetos o ropa contaminados). En algunos casos, 
la infección se propaga de unas regiones corporales a otras ${ }^{4}$. Esto hace que sea fundamental la exploración física minuciosa ante el hallazgo de una tiña, incluyendo siempre las uñas y el cuero cabelludo.

Para el diagnóstico de las dermatofitosis, es fundamental la adecuada toma de muestras por raspado cutáneo del borde activo de la lesión. Esto nos permite la confirmación inmediata con la visualización de hifas septadas en la preparación con hidróxido potásico al $10 \%$. Conocer específicamente el agente causal nos llevará más tiempo, ya que los dermatofitos tardan en crecer en cultivo entre 2 y 4 semanas ${ }^{5}$.

En lo que respecta al tratamiento, en la mayoría de los casos, es suficiente con el empleo de alilaminas o azoles tópicos. Sin embargo, en las formas extensas, refractarias o bien si hay afectación de varias uñas, es necesario instaurar tratamiento oral, siendo el fármaco de primera elección la terbinafina. En pacientes inmunodeprimidos o polimedicados con tiñas extensas u onicomicosis, es recomendable la terapia secuencial, que se basa en el inicio de terapia antifúngica tópica (terbinafina y ciclopirox en barniz para uñas con tecnología hidrosoluble) previa a la instauración del tratamiento oral ${ }^{6}$.

En el caso de nuestra paciente, debido a complicaciones derivadas del trasplante, no ha sido posible iniciar tratamiento oral, por lo que se ha iniciado tratamiento tópico con el fin de aliviar los síntomas y disminuir la contagiosidad.

Aunque las infecciones por dermatofitos son habituales en la práctica clínica, no se conoce su prevalencia real.

Pese a que lo común es que se presenten como una lesión única, es conocida la tendencia a la diseminación en pacientes inmunodeprimidos (infección por el virus de la inmunodeficiencia humana [VIH], tratamientos con corticoides) o atópicos ${ }^{7}$.

Dentro de este grupo de pacientes, ocupan un importante porcentaje los receptores de trasplan- tes de órgano sólido. Aunque parece que las dermatofitosis no son más frecuentes en estos enfermos que en la población general ${ }^{7}$, en la literatura hay múltiples referencias de infecciones por dermatofitos generalizadas, la mayoría de ellas, en trasplantados renales ${ }^{8,9}$.

En las últimas décadas, el aumento incesante del número de trasplantes hace que un número creciente de pacientes estén sometidos a un estado de inmunodepresión prolongada.

Consideramos que la vigilancia periódica de estos pacientes es fundamental para la detección temprana de lesiones cutáneas, tanto tumorales como infecciosas, por lo que el dermatólogo debe formar parte del equipo médico de los pacientes trasplantados para garantizar su atención integral.

Mi paciente no se ha curado de su infección por hongos dermatofitos, pero ha mejorado, y se siente atendida en todos los aspectos de su salud.

\section{BIBLIOGRAFÍA}

1. Seebacher C, Bouchara JP, Mignon B. Updates on the epidemiology of dermatophyte infections. Mycopathologia. 2008;166(5-6):335-52.

2. Segurado Rodríguez A, González Guerra E, Romero Aguilera G. Dermatosis causadas por hongos. En: Guerra Tapia A (ed.). Manual y atlas de las enfermedades de la vulva. Barcelona: Editorial Glosa; 2006. p. 78-100.

3. López-Estebaranz JL, Sopena-Barona J. Dermatofitosis cutáneas. Etiología, epidemiología y manifestaciones clínicas. Med Clin (Barc). 2006;126(Supl 1):14-9.

4. Imbernón-Moya A, Churruca-Grijelmo M, Martínez-Pérez M, Pablo-Hernando E. Placas circinadas eritematodescamativas generalizadas. Piel. 2015;30(3):200-2.

5. del Boz J, Padilla-España L, Crespo-Erchiga V. Toma de muestras y examen directo en dermatomicosis. Actas Dermosifiliogr. 2016;107(1):65-7.

6. Pereiro Ferreiros Jr M, García-Martínez FJ, Alonso-González J. Actualización en el tratamiento de las micosis cutáneas. Actas Dermosifiliogr. 2012;103(9):778-83.

7. García de Acevedo B, Villa A, Hernández-Hernández F, LópezMartínez R, Llorente L, Orozco-Topete R. Tiñas multifocales y localizadas en pacientes inmunosuprimidos. Rev Iberoam Micol. 2008;25(1):32-6.

8. Güleç AT, Demirbilek M, Seçkin D, Can F, Saray Y, Sarifakioglu $E$, et al. Superficial fungal infections in 102 renal transplant recipients: a case-control study. J Am Acad Dermatol. 2003;49(2):187-92.

9. Budihardja D, Freund V, Mayser P. Widespread erosive tinea corporis by Arthroderma benhamiae in a renal transplant recipient: case report. Mycoses. 2010;53(6):530-2. 